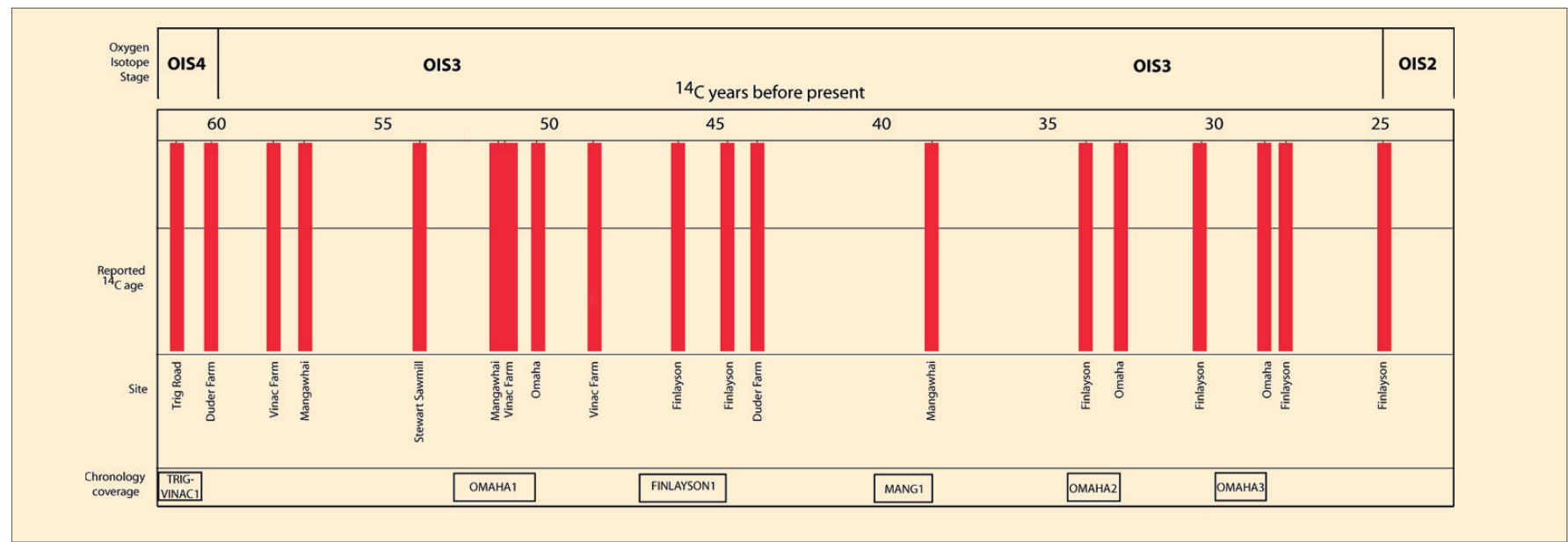

Figure 2: Chronologies and distribution of finite a-cellulose ${ }^{14} \mathrm{C}$ ages obtained on sub-fossil Agathis australis (Northland, New Zealand) - modified from Turney et al., accepted).

additional assurance that their carbon content is truly representative of atmospheric $\mathrm{CO}_{2}$ at the time of growth. The principal sources of uncertainty that have plagued other attempts at calibration in this time range are thereby avoided. We have shown the considerable potential of New Zealand kauri (Agathis australis) for developing long floating sections of calibration curve in the time period 26-60 kyr BP and the LSC and AMS techniques that are required to obtain precise and reproducible ages at these older time periods. It must be remembered that IntCal04 teams took approx. 30 years to build 26,000 years of chronology. Although significant progress has been made with the kauri, a considerable investment in both time and resources will be necessary if this enormous task is to be completed.

\section{References}

Balter, M., 2006: Radiocarbon dating's final frontier, Science, 313: 15601563.

Hogg, A.G., Fifield, L.K., Palmer, J.G., Turney, C.S.M., Galbraith, R. and Robertson, S.A., Robust radiocarbon dating of wood samples by high sensitivity liquid scintillation spectroscopy in the 50 - $70 \mathrm{ka}$ age range. Radiocarbon, submitted.
Hogg, A.G., Fifield, L.K., Palmer, J.G., Turney, C.S.M., Galbraith, R. and Robertson, S.B., Dating ancient wood by high sensitivity liquid scintillation counting and accelerator mass spectrometry - pushing the boundaries. Quaternary Geochronology, accepted.

Palmer, J., Lorrey, A., Turney, C.S.M., Hogg, A.G., Fifield, L.K., Baillie, M.G.L. and Ogden, J., 2006: Extension of New Zealand kauri (Agathis australis) tree-ring chronologies into Oxygen Isotope Stage (OIS)-3, Journal of Quaternary Science, 21(7): 779-788.

Turney, C.S.M., Fifield, L.K., Palmer, J.G., Hogg, A.G., Baillie, M.G.L., Galbraith, R., Ogden, J., Lorrey, A. and Tims, S.G., Towards a radiocarbon calibration for oxygen isotope stage 3 using New Zealand kauri (Agathis australis). Radiocarbon, accepted.

Turney, C.S.M., Roberts, R.G. and Jacobs, Z., 2006: Progress and pitfalls in radiocarbon dating, Nature, 443: doi: 10.1038/nature05214.

\title{
Marine reservoir corrections and the calibration curve
}

\section{R. W. Reimer And P. J. Reimer}

${ }^{14} \mathrm{CHRONO}$ Centre for Climate, the Environment, and Chronology, Queen's University Belfast, UK; r.reimer@qub.ac.uk

The surface ocean carbon reservoir is variable both spatially and temporally, causing calibration of radiocarbon dates of organisms that have taken up marine carbon to be fraught with uncertainty. The paucity of reservoir age data that existed in 1993 on the publication of the seminal paper on the technique (Stuiver and Braziunas, 1993) has been alleviated to some extent. The largest archive of published $\Delta \mathrm{R}$ data, which is located at http://calib. org/marine, now contains more than 800 entries (Fig. 1). However, these data are of varying usefulness in determining the apparent age of the ocean water where they were collected. The following paragraphs will outline the considerations to make in combining, or averaging, available data to form a $\Delta R$ estimate for a particular locality, focusing initially on Holocene samples for which modern day $\Delta R$ are likely to be valid. Recommendations for the improvement of data quality will be made, followed by a discussion of how time variability should be incorporated in $\Delta R$ values.

$\Delta R$ is calculated by obtaining independent calendar and radiocarbon ages

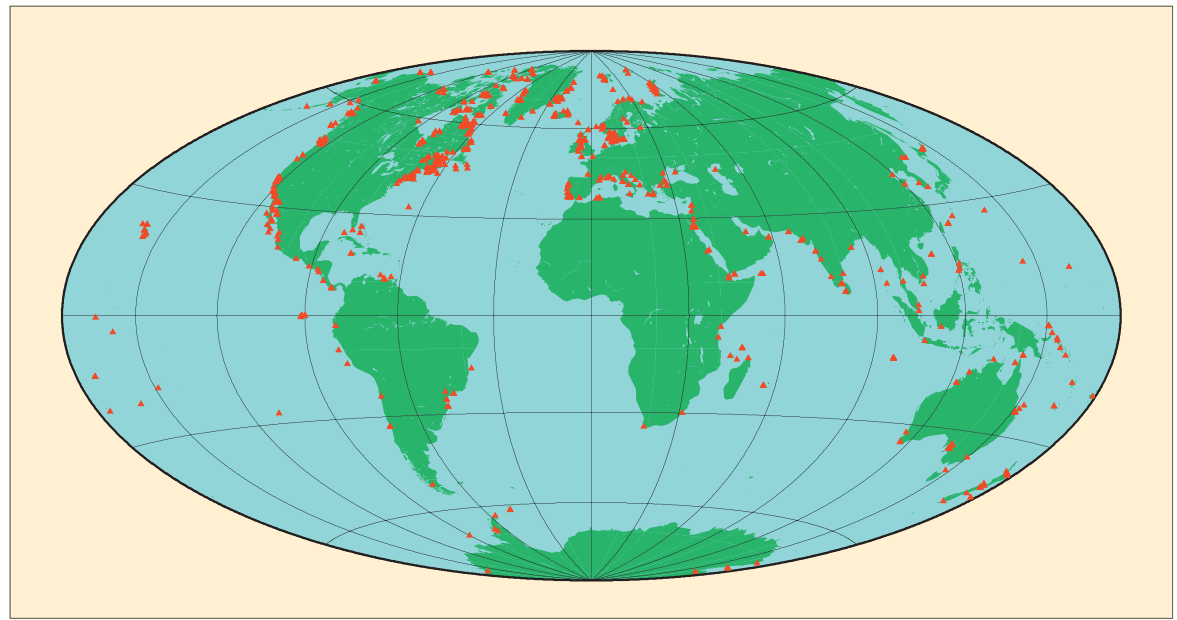

Figure 1: Locations of $\Delta R$ values in the Marine Reservoir Correction Database; $h$ ttp://calib.org/marine.

for an organism that has sampled marine carbon. The most straightforward method to obtain the calendar age is to ascertain the year of death of the organism from historical records. It may also be obtained by carbon dating a terrestrial sample that can be unambiguously paired with a marine sample. Modern (post bomb) samples are avoided for this purpose because the distribution and ocean uptake of ${ }^{14} \mathrm{C}$ derived from atmospheric weapons testing is highly variable. Once the cal age is known, it is used to look up a ${ }^{14} \mathrm{C}$ age in the 'global' marine calibration curve. The difference between this ${ }^{14} \mathrm{C}$ age and the measured ${ }^{14} \mathrm{C}$ age of the marine sample is defined as $\Delta R$. A Bayesian technique that relaxes the contemporaneity requirement between the terrestrial and marine samples has been developed (Jones and Nicholls, 2002) to quantify uncertainty in the match up of the calendar ages of the paired samples. 


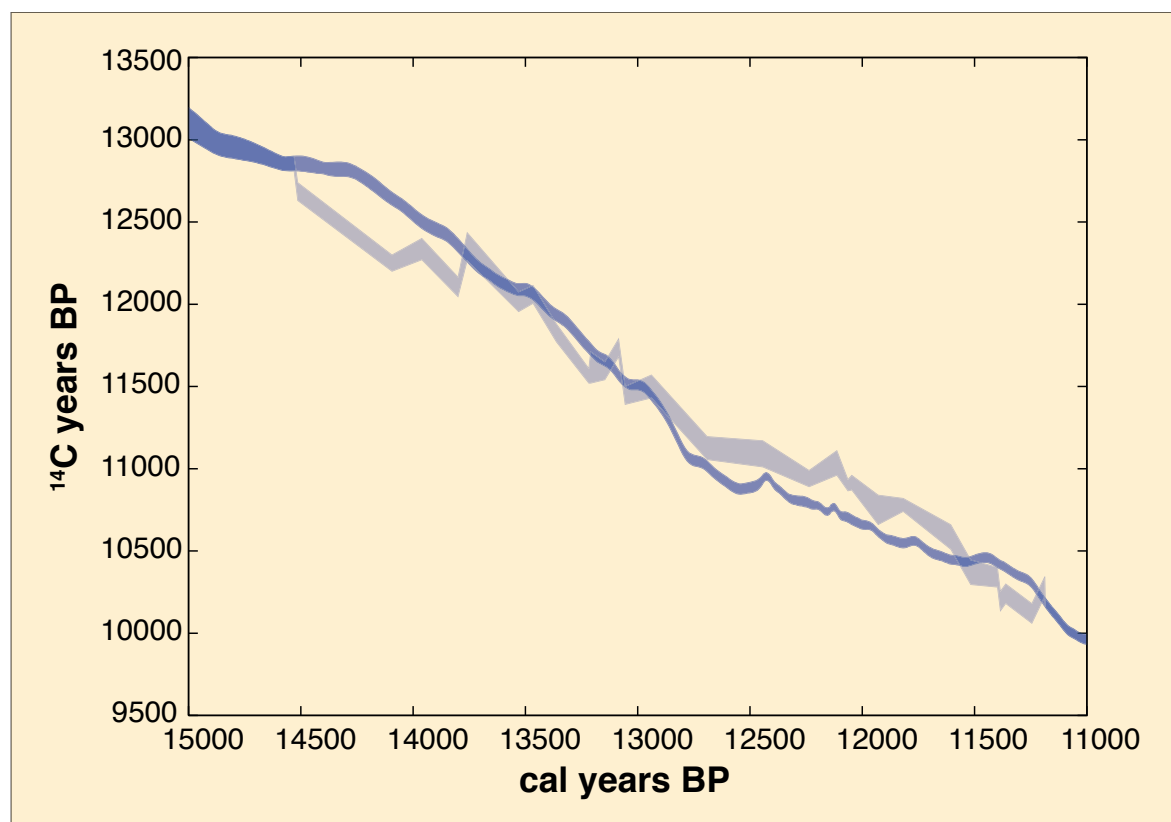

Figure 2: An example of a "curve snippet" derived from measurements by Bondevik et al. (2006) shown with the Marine 04 curve in the dark color for comparison.

Before published $\Delta R$ data is accepted for consideration, an assessment must be made of whether the organism that was used to determine $\Delta \mathrm{R}$ took up dead carbon in its lifetime, as for example, gastropods may do. A known value of $\Delta R$ may be unusable for general marine calibration purposes if the dated material was influenced by carbonates or other sources of old carbon taken up during the organism's feeding process. Difficulty may also arise if the $\Delta R$ is derived from a scavenger that has made a diet of animals that take up old carbon. In this case, a determination must be made of whether the old carbon is taken into its soft body tissue or only into the shell. The $\Delta \mathrm{R}$ database at the calib.org website was recently expanded to contain dietary preferences of the dated material but much work remains to be done in populating these fields with data. The participation of a biologist would greatly help in identifying database records that are suspect due to old carbon influence. The problem acquires an additional dimension when realizing that bottom-scraping feeders may be suitable indicators of ocean age if there are no carbonates in their habitat, or if the sample needing calibration is of the same species in the same environment.

Generally, $\Delta R$ is not available at the precise location of the sample in question, so an estimate must be made of which nearby $\Delta R$ values are most likely suitable for inclusion. This requires knowledge of local ocean currents. Ideally, only $\Delta R$ values that are from the precise location or 'upstream' of the site in question should be used. Recently, a compilation of known regional ocean-current information was begun at http://calib.org/marine. Presum-

the dating of Holocene samples, during have used different values for this offset, depending on the state of knowledge at the time the curve was constructed. Future versions of IntCal will need to reflect the knowledge we have gained of the time variability of the reservoir age.

We now present a recommendation for dealing with time dependence of $\Delta R$ during calibration. This problem has been addressed in the literature (Deo et al., 2004) but generally in an ad hoc fashion. We propose that a Bayesian offset model, similar to the one developed for the Southern Hemisphere calibration curve (Buck and Blackwell, 2004), be developed for $\Delta R$. The model would use $\Delta R$ values available through time to generate a varying offset from the marine calibration curve. During time periods when $\Delta R$ is not time dependent, the offset model would produce a smooth transition into the marine curve plus constant $\Delta \mathrm{R}$. The $\Delta \mathrm{R}$ database at calib. org would be modified so that 'curve snippets' would become part of the data record, and calibration programs would have to be modified to use these snippets (Fig. 2). This approach represents a step away from the current paradigm of a constant regional $\Delta R$ value applied to a global curve, and effectively introduces regional calibration curves. However, it deals effectively with the problem of a calibration that extends beyond the time period of which we have knowledge of $\Delta R$ variability, and falls back to the global baseline marine calibration.

http://calib.org/marine is currently hosted and maintained by the ${ }^{14} \mathrm{CHRONO}$ Centre at Queens University Belfast, Belfast, Northern Ireland.

\section{Note}

Data used in this study is available at: http://calib.org/marine which time it can often be assumed that little change in major ocean circulation occurred. This is not strictly true, of course, as regions where there is upwelling of deep ocean water have shown significant differences in $\Delta R$ during the Holocene (Soares and Dias, 2006). During the last glaciation and termination, however, there were potentially larger and more widespread changes (Bondevik et al., 2006; Sarnthein and Grootes, 2006; Grootes and Sarnthein, this issue). The problem of temporal variability in the marine reservoir age also enters into the construction of the marine calibration curve itself. The procedure for constructing this curve from multiple data sets involves correcting each data set to a global value and then determining the average offset of that curve from the atmospheric curve. Different versions of IntCal

\section{References}

Bondevik, S., Mangerud, J., Birks, H.H. Gulliksen, S. and Reimer, P., 2006 Changes in North Atlantic radiocarbon reservoir ages during the Allerod and Younger Dryas, Science, 312: 1514-1517.

Buck, C.E. and Blackwell, P.G., 2004: Formal statistical models for estimating radiocarbon calibration curves, Radiocarbon, 46: 10931102

Deo, J.N., Stone, J.0. and Stein, J.K., 2004: Building confidence in shell: Variations in the marine radiocarbon reservoir correction for the northwest coast over the past 3,000 years, American Antiquity, 69: 771-786.

Jones, M. and Nicholls, G., 2002: New Radiocarbon Calibration Software. Radiocarbon, 44(3): 663-674

Sarnthein, J.M. and Grootes, P.M., 2006: ${ }^{14} \mathrm{C}$ reservoir ages and changes in ocean circulation during early deglacial times. In: 19th International Radiocarbon Conference Abstracts \& Programme, Oxford: 235.

Soares, A.M.M. and Dias, J.M.A., 2006: Coastal upwelling and radiocarbon - Evidence for temporal fluctuations in ocean reservoir effect off Portugal during the Holocene, Radiocarbon, 48: 45-60.

Stuiver, M. and Braziunas, T.F., 1993: Modeling Atmospheric C-14 Influences and C-14 Ages of Marine Samples to 10,000 Bc, Radiocarbon, 35: 137-189. 